\title{
Diagnosis of left adrenal paracoccidioidomycosis by endoscopic ultrasound fine needle aspiration
}

Paracoccidioidomycosis is a systemic granulomatous disease endemic in Latin America. It is acquired through the inhalation of spores released by Paracoccidioides brasiliensis [1]. Impairment of adrenal function may be found in $15 \%-20 \%$ of patients with paracoccidioidomycosis [1]. Although highly specific (> 85\%), serological tests may be false-negative in immunosuppressed patients [1]. Hence, detection of fungal elements is the diagnostic gold standard. A PubMed review revealed that adrenal biopsies done to diagnose paracoccidioidomycosis are mostly guided either by computed tomography or by abdominal ultrasound [2,3]. This is the first case report of diagnosis of paracoccidioidomycosis in the left adrenal gland by endoscopic ultrasound fine needle aspiration (EUS-FNA).

A 40-year-old man with chronic alcoholic pancreatitis and type 2 diabetes mellitus complained of weakness, abdominal pain, and $30 \mathrm{~kg}$ of weight loss in the past 6 months. During the diagnostic investigation, primary adrenal insufficiency was confirmed by the low serum cortisol and high levels of adrenocorticotropic hormone (ACTH). A magnetic resonance scan showed nodular formation (3.5 $\times$ $2.4 \times 4.7 \mathrm{~cm})$ in the left adrenal gland ( $\bullet$ Fig. 1). As the patient had a positive history for tuberculosis and paracoccidioidomycosis, he was investigated for presence of these pathogens. Catarrh assessment revealed absence of both paracoccidioidomycosis and tuberculosis organisms and serological tests were also negative. Endoscopic ultrasonography with FNA was carried out ( $\bullet$ Fig. 2 ) and the histopathological analysis revealed $P$. brasiliensis spores ( Fig. 3). The patient was treated with amphotericin-B with complete remission after 60 days.

Percutaneous adrenal puncture has been standard practice in the diagnosis of paracoccidioidomycosis of the adrenal gland, with severe complications reported such as hematuria, pancreatitis, and pneumothorax [4]. Nowadays, EUS-FNA of the left adrenal is a safe and reliable method, with low morbidity and high rate of accuracy [5], and this is the first report of diagnosis of adrenal paracoccidioidomycosis by EUS-FNA.

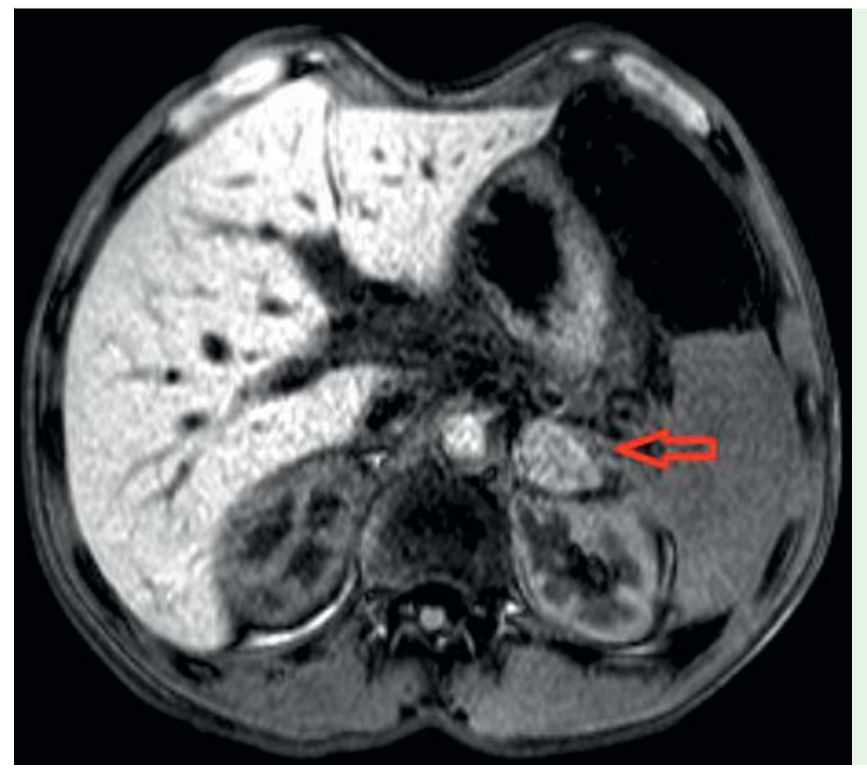

Fig. 1 Magnetic resonance image showing nodular formation in the left adrenal gland (arrow).

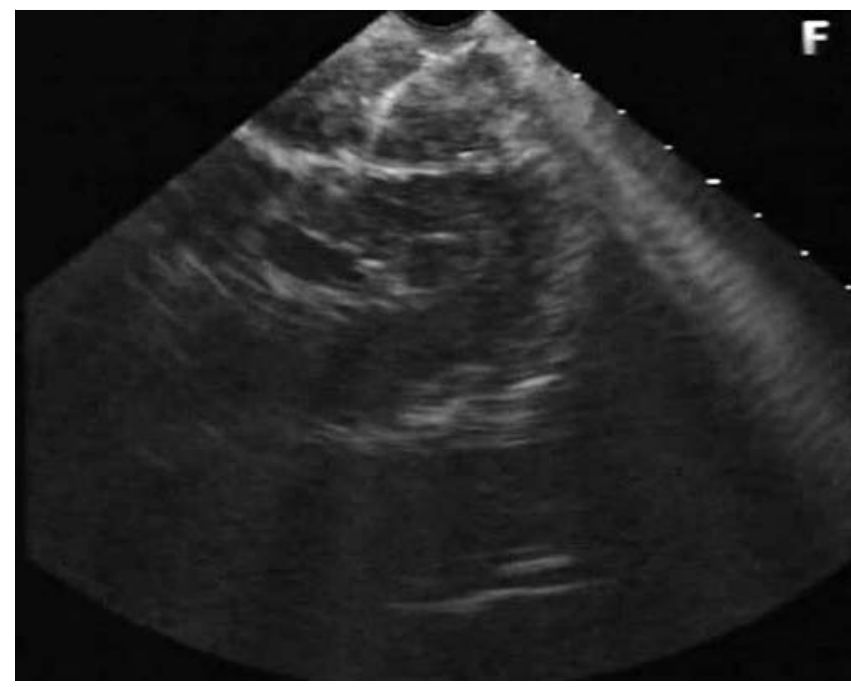

Fig. 2 Endosonography: fine needle aspiration of the left adrenal gland.

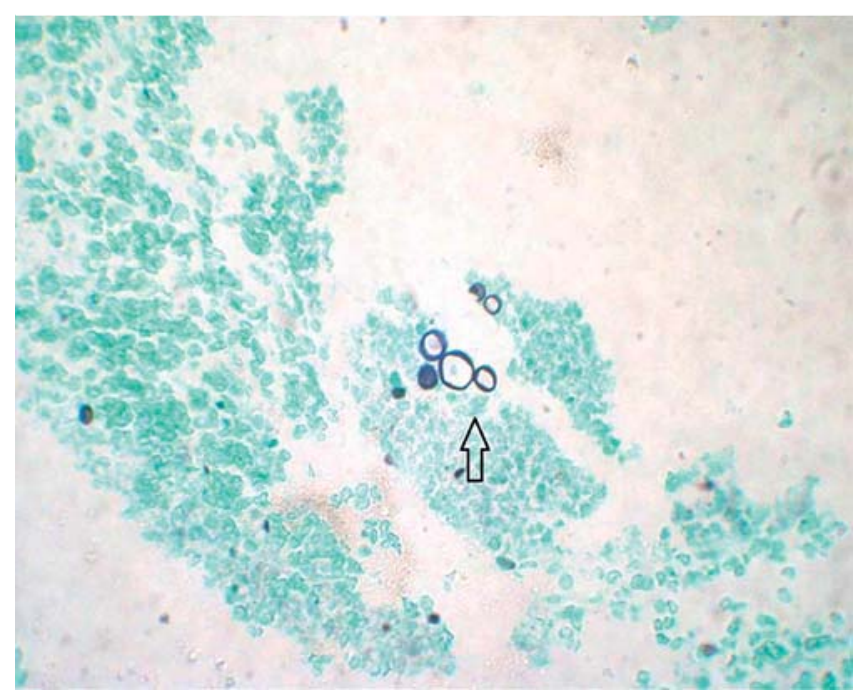

Fig. 3 Histopathological section showing spores with black capsules (arrow) (Grocott silver stain, $\times 40)$. 
Endoscopy_UCTN_Code_CCL_1AF_2AG_3AD

\section{Competing interests: None}

R. Colaiacovo ${ }^{1}$, R. L. Ganc ${ }^{1}$, A. C. Leone ${ }^{1}$, M. T. Medeiros ${ }^{2}$, L. G. Rossini ${ }^{1}$

1 French-Brazilian Center of Endoscopic Ultrasound, Department of Endoscopy, Santa Casa Faculty of Medicine, São Paulo, Brazil

2 Department of Pathology, Santa Casa Faculty of Medicine, São Paulo, Brazil

\section{References}

1 Shikanai-Yassuda MA, Telles-Filho FQ Mendes RP et al. Guidelines in paracoccidioidomycosis. Rev Soc Bras Med Trop 2006; 39 (3): $297-310$

2 Faiçal S, Borri ML, Hauche OM, Ajzen S. Addison's disease caused by Paracoccidioides brasiliensis: diagnosis by needle aspiration biopsy of the adrenal gland. AJR Am J Roentgenol 1996; 166: $461-462$

3 Agudelo CA, Muñoz C, Ramírez A et al. Identification of Paracoccidioides brasiliensis in adrenal glands of two patients with paracoccidioidomycosis and adrenal insufficiency. Rev Inst Med Trop Sao Paulo 2009; 51 (1): $45-48$

4 Arellano RS, Harisinghani MG, Gervais DA et al. Image-guided percutaneous biopsy of the adrenal gland: review of indications, technique, and complications. Curr Probl Diagn Radiol 2003; 32: 3

5 Eloubeidi MA, Black KR, Tamhane A et al. A large single-center experience of EUS-guided FNA of the left and right adrenal glands: diagnostic utility and impact on patient management. Gastrointest Endosc 2010; 71: $745-753$
Bibliography

DOI $10.1055 / \mathrm{s}-0030-1256462$

Endoscopy 2011; 43: E236-E237

(c) Georg Thieme Verlag KG Stuttgart · New York . ISSN 0013-726X

\section{Corresponding author}

\section{R. Colaiácovo}

French-Brazilian Center of Endoscopic Ultrasound, Department of Endoscopy, Santa Casa Faculty of Medicine Rua Jose Alberto Senator

18 Vila Romana

São Paulo SP 05043-070

Brazil

rogerio_colaiacovo@yahoo.com.br 